\title{
DIGITAL GAMING: ORGANIZING FOR SUSTAINABLE INNOVATION
}

\author{
J. P. Allen ${ }^{1}$ and Jeffrey Kim ${ }^{2}$ \\ ${ }^{I}$ Masagung Graduate School of Management, University of San Francisco, USA ${ }^{2}$ Information \\ School, University of Washington, USA
}

\section{INTRODUCTION}

Digital gaming has caught the attention of the management world because of its amazing growth rate-the largest massively multiplayer online games, running 24 hours a day, now have millions of subscribers, and host hundreds of thousands of players simultaneously-and perhaps because of its 'sexy' subject matter. But digital gaming also offers one of the most extreme examples of the need for continuous and rapid IT innovation. Games must constantly innovate to preserve the long-term interest of paying, voluntary players that seek a vibrant community and a compelling experience.

In this paper, we discuss digital gaming as an example of 'experiential' IT (Rosenbloom, 2003) that likely will have applications beyond today's gaming industry. We outline a research agenda around the question of how digital games are able to change in order to stay alive and vibrant over the long term-how do the relevant social groups organize themselves for sustainable innovation? We propose a theoretical approach based on sociotechnical change theory. A sociotechnical change approach attempts to unpack the amazing amount of social and technological diversity associated with digital gaming, in a way that will move the research literature beyond a discussion of 'technological features' on one hand, and the 'impacts' of games on the other. 


\section{DIGITAL GAMING AND IT INNOVATION}

The innovation demands of digital gaming are particularly intense. This section of the paper defines more precisely what those innovation demands are, the nature of the business problem faced by gaming organizations, and how we define a research agenda to investigate these challenges.

\subsection{Innovation demands of gaming}

Digital gaming has been defined as 'experiential' IT (Rosenbloom, 2003). Our typical view of IT is to design a technology for specific information processing functions, then have it adopted and used by endusers. "In experiential environments, users apply their senses directly to address information related to an event (such as a business transaction or even a college football game)." (Rosenbloom, 2003; p. 29) Digital games, as an experiential IT, succeed by creating environments for exploration and interaction that immerse players in an artificial world. Classic literary techniques such as scenario, character, and storyline are combined with IT to make digital gaming memorable, engaging, and even compelling (Bushnell, 1996).

A new and difficult challenge of experiential IT is the demand for constant change, over a relatively long period of time, in order to preserve an engaging and compelling experience. "The driving force in these immersive, realistic environments is the user's experience, not merely a specification." (Rosenbloom, 2003, p. 31) The relationship between IT producers and customers in experiential IT takes on a whole new flavor. Producers and users constantly interact to produce the day-to-day innovation that will keep a community of digital players vibrant and alive. Experiential IT demands sustainable innovation-not just one-time during specification and design, or even in occasional new releases.

\subsection{The business challenge of sustainable innovation}

The business challenged faced by organizations trying to produce digital gaming is to keep customers playing (and paying) as long as possible. Stateof-the-art experiential IT does not come cheap. A successful multiplayer, online gaming environment is the equivalent of a "moonshot," according to Game Developer magazine (February, 2003). "It's expensive, technically difficult, and can take years to complete, and yet everyone wants to give it a try."

After a difficult and expensive beginning, then the need for sustainable innovation arises over the longer term: a steady stream of new content, new 
storylines, new challenges, and new capabilities, along with the need to adjust technology, regulations, and even the interactions between players. The players, as they try to create vibrant communities, have a tremendous influence on the future directions of the digital game. The need for continuous innovation in experiential IT blurs the line between product and service.

The scale and speed of interaction among players is another distinctive characteristic of digital gaming. The largest M.M.O.R.P.G. ("massively multiplayer online role-playing game" such as Lineage in South Korea, or Everquest in the US) can have millions of subscribers and hold as much as 100,000 players in the same virtual game space at the same time. Players interact within the game in sophisticated and complex ways. "Game designers...have found that their models are realistic enough to engender many of the same phenomena that exist in the real world, including market pricing, civic organization, friendship, environmental shortages, hyperinflation, theft, murder, and inheritance." (Lovejoy, 2002) In a vibrant game such as Everquest, players average over 5 hours per day playing time, and spend on average more than 800 hours developing their virtual characters. (Lovejoy, 2002)

Players can also interact outside of the game. Interactive web games, for example, attract players who will volunteer to solve puzzles in the game collectively. In the case of one interactive web game (The Beast), players created their own website (www.cloudmakers.org) to exchange suggestions and possible solutions to the game puzzles. As players put together the clues left in the game space and solved the puzzles, new puzzles were added by the main creator of the game story (a science fiction author). As the players banded together, puzzles were solved more quickly, increasing even further the rate at which new game innovations had to be introduced. After trying to keep up with a community of 7,000 players over three months, the main storyteller confessed that it was one of the most intense and demanding writing experiences of his life (personal communication, September 2003).

If these digital games are any indication, experiential IT will require sustained innovation to cope with the active role that 'users' play in the evolution of the product/service itself. Already, the 'customer service' needs of online, multiplayer gaming are proving somewhat unique. Sony, the developer of Everquest, hires over 100 expert gamers to constantly intervene, appearing in the game as characters to help organize players and resolve disputes, or to "go invisible" and "investigate those suspected of violating the rules or wreaking virtual havoc" (Walker, 2003). Dozens of programmers "continually add fresh weaponry, skills and adventures to each game. Unlike most short-lived PC games, massively multiplayer online games constantly evolve in an attempt to keep players engaged." Thanks to 
this constant innovation, the average Everquest player stays at least 10 months.

\subsection{The research agenda}

Our research agenda is to better understand how to produce experiential IT. In particular, how do producers organize their work activities to create the sustainable innovation that experiential IT seems to require? For digital gaming specifically, we want to better understand how producers organize the work of changing the game over time to create a vibrant, compelling experience that keeps players coming back for more.

We suspect that the unique features of experiential IT innovation will reveal themselves along the following work dimensions:

- Developer-Player: 'Users' are intimately involved in the direction of innovation, and interact among themselves.

- Developer-Developer: The range of talent required to develop digital gaming is diverse. It includes programmers and network specialists, but also artists, writers, and producers. How will members of these different communities interact to produce IT-based innovation?

- Developer-Sponsor: Business strategists, investors, and outside clients will place their own demands on digital gaming. How will the need for cost controls, for example, impose itself on the creative innovation required for experiential IT?

\section{SOCIOTECHNICAL CHANGE THEORY}

Our approach to studying sustainable innovation is based on sociotechnical change theory. In this section of the paper, we present our theoretical approach, why it fits with the problem of IT innovation in gaming, and discuss how we believe our approach will move the research literature forward.

\subsection{A sociotechnical view of gaming}

Sociotechnical change theory, as defined by Bijker (1995), refers to a school of technological change theory that has emerged from the sociology of technology community. Sociotechnical change theory includes a number of different research traditions (including, for example, social construction of technology, and actor-network theory) that share common features. Sociotechnical change theory views technology as an accomplishment, 
whose successful stabilization into a particular useful form needs to be explained as a combination of social and technical elements, and not simply as a victory of 'superior' technology.

We argue that any attempt to describe how modern digital games are created, stabilized, and evolve would benefit from this sociotechnical approach (Bijker et al, 1987; Bijker and Law, 1992). Sociotechnical change theory highlights the diverse interactions of the groups involved in game evolution, including artists, programmers, technicians, business strategists, expert players, casual players, activists and hackers. This sociotechnical approach focuses on gaming itself as a process involving complex associations between different social/technical elements, creating a mix of digital technology, product, and service that itself provides a venue for social interaction. The questions asked by a sociotechnical change study include: "Why did designers think this way rather than that? What assumptions did the engineers, or the business people, or the politicians, make about the kinds of roles that people — or indeed machines - might play in the brave new worlds they sought to design and assemble? What constraints did they think about-or indeed run into-as they built or deployed their technologies? What were the uses-or abuses-to which the technologies were put by their users once they were deployed? How, in other words, did users themselves reshape their technologies? And how did the users and their technologies shape and influence future social, economic, and technical decisions?" (Bijker et al, 1992)

Research informed by sociotechnical change theory must study the interactions between these diverse groups that lead to specific technological decisions. It also focuses on the assumptions held by different participants about the proposed roles for people and technology in a newly proposed system. The set of concerns in digital game design span traditional technical problems, such as allocating network resources (Smed et al, 2002), and traditional social problems, such as preventing technically sophisticated players from cheating. In reality, these problems are difficult to separate into distinct social and technical issues.

\subsection{Moving the literature forward}

The current literature on digital gaming and innovation is mainly in two areas. The first literature focuses on game development, and which specific technology features lead to successful games. The second focuses on the psychological or cultural impact of games. Both literatures rely on technology-centric, even technological determinist assumptions with wellknown limitations for understanding complex sociotechnical situations (e.g., Kling, 1996). 
Our approach, based on sociotechnical change theory, tries to move beyond discussions of technology features and technology impacts. It views digital gaming as a rapidly changing production system in which the IT product and service are a complex ensemble of social and technical elements. We believe that success with experiential IT will improve with a more systematic knowledge of its sociotechnical production process.

\section{POSSIBLE CONTRIBUTIONS}

As we write this paper, our study of digital gaming is just starting its fieldwork stage. This section of the paper discusses the kinds of results we anticipate, and the potential wider significance of our work.

\subsection{Structure of the study}

We begin our study with an initial in-depth case study of digital gaming. The focus will be on changes made to the game, particularly after its initial release. We will investigate the interactions that led to each change, and how specific social/technical decisions were shaped by the problematizations employed by different social groups (Callon, 1987).

Techniques for mapping and coding sociotechnical networks are still in their infancy. We hope to use some variant of the script idea from actornetwork theory (Bijker and Law, 1992) to reduce participant interactions to a manageable level of complexity. The scripts specify the roles that different network elements, both human and non-human, are supposed to play in a proposed system. Another possibility is to use the technological frame concept (Bijker, 1995) to capture the problems, solutions, and problem solving techniques employed by different technological communities. The inclusion of individuals in different technological frames helps explain why technological innovation proceeds in some directions rather than others.

\subsection{Wider significance of digital gaming innovation}

While digital gaming has an intrinsic interest for students of IT, organizations, and society (Poole 2000), we believe that elements of digital gaming will find their way to other kinds of important technologies, products, and services (Rosenbloom 2003). Features of experiential IT usually associated with gaming are being introduced into other kinds of IT products and services in areas such as advertising, education, and organizational collaboration. Bushnell (1996; p. 34) asks "is there a new 
piece of game software that when played well will create a business plan for the player? Is there a game that trains a sales force on a newly released product? Are there games that can become the answer to declining scores and capabilities of the nation's school children?" Knowledge of more userdriven production processes, already seen in gaming applications (e.g., Kushner, 2003), could be essential for deploying experiential IT in other domains.

The demands of organizing for sustainable innovation challenge some of our traditional assumptions about the nature of IT innovation. The IT literature has stressed the importance of clear specifications, listening to users, and even observing users. We argue that this view does not begin to capture the diversity of roles that game players assume in the production of experiential IT. A better understanding of innovation processes for experiential IT will hopefully lead us to an improved understanding of IT innovation as a whole.

\section{REFERENCES}

Bijker, W.E. Of Bicycles, Bakelite, and Bulbs: Towards a Theory of Sociotechnical Change. MIT Press, Cambridge, Massachusetts, 1995.

Bijker, W.E., Hughes, T.P., and Pinch, T. (eds.) The Social Construction of Technological Systems: New Directions in the Sociology and History of Technology. MIT Press, Cambridge, Massachusetts, 1987.

Bijker, W.E., and Law, J. (eds.) Shaping Technology/Building Society: Studies in Sociotechnical Change. MIT Press, Cambridge, Massachusetts, 1992.

Bushnell, N. "Relationships between fun and the computer business," Communications of the ACM (39:8) 1996, pp. 31-38.

Callon, M. "Society in the Making: The Study of Technology as a Tool for Sociological Analysis," in Bijker et al., 1987.

Kling, R. Computerization and Controversy: Value Conflicts and Social Choices. Academic Press, San Diego, 1996.

Kushner, D. Masters of Doom: How Two Guys Created an Empire and Transformed Pop Culture. Random House, New York, 2003.

Lovejoy, K. "Playing for real," Regional Review - Federal Reserve Bank of Boston (12:4) 2002, p. 1.

Poole, S. Trigger Happy: Videogames and the Entertainment Revolution Arcade Publishing, New York, 2000.

Rosenbloom, A. "A game experience in every application: Introduction," Communications of the ACM (46:7) 2003, pp 28-31.

Smed, J., Kaukoranta, T., and Hakonen, H. "Aspects of networking in multiplayer computer games," The Electronic Library (20:2) 2002, pp. 87-97.

Walker, L. "Game worlds in creation," The Washington Post June 26, 2003, p. E1. 